PRODUCTION

ENGINEERING ARCHIVES
2014, Vol. 3, No 2, pp 35-38

ISSN 2353-5156

ISSN 2353-7779 (print version)

(online version)

Article history: $\quad$ Received: 14.05.2014

Accepted: 15.06.2014

Online: 31.07 .2014

Available online on: http://www.qpij.pl

Exist since $4^{\text {rd }}$ quarter 2013

\title{
The enterprise constant improvement by using medium ratings differentiation analysis on the second Toyota principle
}

\author{
Stanisław Borkowski ${ }^{1}$, Renata Stasiak-Betlejewska ${ }^{2}$ \\ ${ }^{1}$ Institution of Production Engineering, Faculty of Management, Czestochowa University of Technology, Al. Armii Krajowej 19B, 42-201 \\ Częstochowa, Poland, e-mail: bork @zim.pcz.pl \\ ${ }^{2}$ Institution of Production Engineering, Faculty of Management, Czestochowa University of Technology, Al. Armii Krajowej 19B, 42-201 \\ Częstochowa, Poland, e-mail: renatastasiak@wp.pl \\ "Corrensponding author: tel.: +48 343250 333, e-mail: renatastasiak@wp.pl
}

\begin{abstract}
The organization constant improvement process is possible using a step by step method. The self-learning organization and continuous improvement of the organization's culture guarantees achievement of good market results and raising competitiveness. This paper aims to identify and analyze the ratings importance level for the production process factors in order for the manufacturing process to improve in the chosen construction company. The study used an innovative research method BOST, which refers to the Toyota management principles in the production and the service organizations. As a result of research the ratings differentiation importance level for the production process factors was achieved which provides a basis for the process of the analyzed company to improve.
\end{abstract}

Key words - constant improvement, Toyota principles, BOST, construction company

\section{Introduction}

The second Toyota management principle is based on the conviction that the appropriate process leads to the relevant results (LIKER J.K. 2005).

The organization process improvement should be implemented on the basis of the above assumption. Identification of the relevant production and service process elements that create added value from the point of clients' and employees' view, provides both good financial performance of the organization and a culture of improvement in the organization (SELEJDAK J. 2013). Well-known Pareto principle 20/80 confirms that the designation of the most rele- vant process elements in accordance with the company features creates opportunities to improve processes with market requirements.

\section{The research methodology BOST}

The research method that was used in the presented research results analysis was the innovative method BOST, that is one of the qualitative techniques using workers and managers opinions with regard to Toyota principles implementation level analysis. This survey method originates from the Toyota production management principles idea included in the authorship 
notion TOYOTARITY that was invented by the BOST method author (BORKOWSKI S. 2012a). The Toyotarity idea includes the constant improvement of the organization by fostering self-learning leading to a whole organization culture improvement through identifying relevant process elements building the value for the enterprise and clients.

The BOST study enables one to examine, among other things, the second Toyota principle, which relates to the identification of relevant production process parameters in order to determine the appropriate methods in accordance with expected results (from the company and customers point of view). The second Toyota principle implies the identification of appropriate processes leading to the corresponding results. In order to identify appropriate processes the BOST method allows (BORKOWSKI S. 2012d) assessment of a significance of factors describing 14 Toyota management principles and the significance of driving improvement process forces,

The analysis medium ratings differentiation on the basis of the second Toyota principle includes research results obtained in the BOST survey, which were elaborated using an authorship software program in the form of statistical elaboration (PUŁASKA-TURYNA B. 2008):

- standard deviation, that illustrates how widely the values given size are scattered around its average. The smaller deviation the observations are more focused around the average. The standard deviation is the square root of the variance,

- variance illustrates differentiation in the obtained research results in the result set (variable). The variance indicates whether the results are more concentrated around the average, if there are small differences between the average and individual results or may be the result dispersion is large,

- coefficient of variation - is a measure of the characteristics distribution differentiation. In contrast to the standard deviation, which determines absolute characteristics differences, the coefficient of variation is a relative measure, which is dependent on the size of the arithmetic average,

- distribution skewness coefficient - a measure of the distribution asymmetry, that takes the value zero for a symmetric distribution, negative values for the distributions with left-sided asymmetry (extended left distribution arm) and positive values for the distributions with right-sided asymmetry (extended right arm of the distribution),

- kurtosis - is a measure of concentration and distribution flattening (the term used in statistics and the probability account). Specifies the distribution and concentration of the (community) near the middle average.

\section{Results and discussion}

The survey BOST was conducted in the chosen enterprise of the construction industry that offers production of the construction elements and the services within building wooden houses. The respondents group includes the enterprise workers. The respondents characteristics are presented in Table 1, which shows the percentage results of the BOST survey, characterizing the respondents due to the following features: gender (MK), education (WE), age (WI), seniority (SC), mobility (MR) and mode employment (TR).

Table 1. E12. Respondents features. The percentage respondents characteristic. Concerns the chosen construction enterprise

\begin{tabular}{|c|c|c|c|c|c|c|}
\hline \multirow{2}{*}{$\begin{array}{c}\text { Sym- } \\
\text { bol }\end{array}$} & \multicolumn{6}{|c|}{$\begin{array}{c}\text { Respondents' features indication and the percentage } \\
\text { characteristic }\end{array}$} \\
\hline & MK & WE & WI & SC & MR & TR \\
\hline 1 & 82 & 21 & 9 & 12 & 30 & 67 \\
\hline 2 & 18 & 21 & 36 & 21 & 30 & 12 \\
\hline 3 & & 27 & 27 & 27 & 9 & 21 \\
\hline 4 & & 30 & 9 & 24 & 6 & \\
\hline 5 & & & 6 & 3 & 15 & \\
\hline 6 & & & $\mathbf{0}$ & 0 & 9 & \\
\hline 7 & & & 3 & 9 & & \\
\hline 8 & 33 & & & 3 & & \\
\hline
\end{tabular}

Source: own study.

As it results from the respondents data, the survey concerns opinions of workers who are mostly men (82\%) with higher education (30\%). The respondents majority is in the age $31 \div 50$, whose current working place is the third one (27\%) employed mostly by regular employment mode (67\%). 
The BOST research survey question analyzed in the paper concerns the second Toyota principle described by using six factors (E3 principle), that were evaluated by respondents group with using ratings $(1 \div 6)$ :

- continuous system of problem detecting (CP),

- production interruption after detecting qualitative problem (PE),

- standard tasks, processes, documents (SZ),

- granting attorney power down (EU),

- using only reliable technology (ST),

- the use of visual inspection (SW).

Table 2 presents the percentage ratings structure of the E3 principle factors validity evaluation.

Table 2. E3. The second Toyota principle. The ratings structure [\%] of the E3 factors validity. Concerns the chosen construction enterprise

\begin{tabular}{|c|c|c|c|c|c|c|}
\hline \multirow{2}{*}{ Ratings } & \multicolumn{7}{|c|}{ Factors' denotation } \\
\cline { 2 - 7 } & $\mathbf{C P}$ & $\mathbf{P E}$ & SZ & EU & ST & SW \\
\hline $\mathbf{1}$ & 0,0 & 0,0 & 18,2 & 36,4 & 6,1 & 39,4 \\
\hline $\mathbf{2}$ & 3,0 & 15,2 & 24,2 & 24,2 & 15,2 & 18,2 \\
\hline $\mathbf{3}$ & 12,1 & 3,0 & 33,3 & 18,2 & 12,1 & 21,2 \\
\hline $\mathbf{4}$ & 24,2 & 12,1 & 9,1 & 6,1 & 33,3 & 15,2 \\
\hline $\mathbf{5}$ & 33,3 & 21,2 & 12,1 & 15,2 & 15,2 & 3,0 \\
\hline $\mathbf{6}$ & 27,3 & 48,5 & 3,0 & 0,0 & 18,2 & 3,0 \\
\hline
\end{tabular}

Source: own study.

The analysis of data shown in Table 2 indicated the following results:

- continuous system of problem detecting (CP) was evaluated by the majority of respondents with a rating $5(33,3 \%)$,

- production interruption after detecting qualitative problem (PE) was evaluated as the most important (6) factor $(48,5 \%)$,

- standard tasks, processes, documents (SZ) in the workers opinion is a less important factor than others,

- granting attorney power down (EU) is perceived by workers as the least significant in the production processes (36,4\% indicated rating " 1 "),

- using only reliable technology (ST) was evaluated as important (rating "4" indicated by 33,3\% of respondents),
- the use of visual inspection (SW) has been indicated as the one of the least important in the production processes improvement.

Graphic presentation of the research findings statistical analysis is presented in Figure 1.
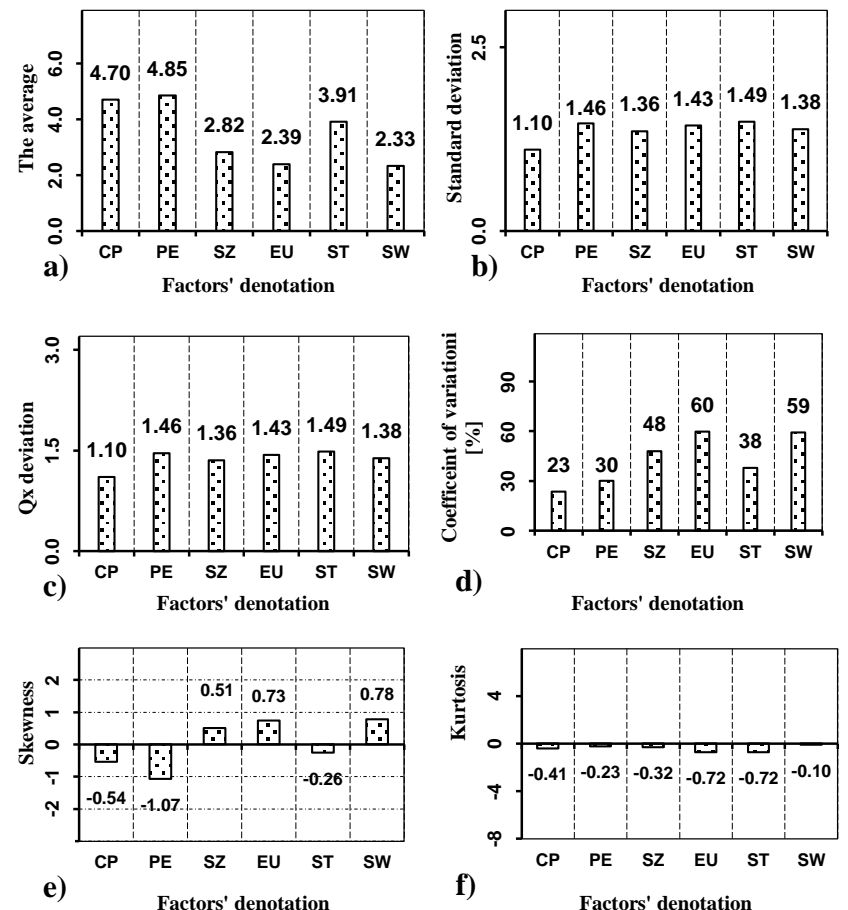

Fig. 1. E3. Principle 2. Comparison of E3 factors: a) average, b) standard deviation, c) $Q x$ deviation, d) coefficient of variation, e) skewness, f) kurtosis.

Concerns the chosen construction enterprise.

Source: own study.

As it results from the data presented in Fig. 1a, that concerns ratings average, PE factor obtained the highest average (4.85). The smallest average (2.39) was obtained by EU factor. The standard deviation has the highest value in the ST factor case (1.49). Qx deviation reaches the highest level for the factor ST (1.49). The coefficient of variation for EU factor reached 60 and it is only about 1 point higher than that value for SW factor (59). On the other hand, the coefficient of variation is the smallest for the CP factor (23). Skewness reached negative level for factors $\mathrm{CP}, \mathrm{PE}$ and ST. Positive levels are reached by factors: SZ, EU and SW. The validity level of the medium ratings differentiation structure for the individual production process elements with regard to the second Toyota principle is presented in Table 3. 
Table 3. E3. The second Toyota principle. Results on validity medium ratings differentiation for E3 factors.

Concerns the chosen construction enterprise

\begin{tabular}{|c|c|c|c|c|c|c|}
\hline \multicolumn{2}{|c|}{ Denotations } & PE & sz & EU & ST & sw \\
\hline \multirow{4}{*}{ CP } & test & 0,48 & 6,17 & 7,31 & 2,44 & 7,67 \\
\hline & $\alpha=\mathbf{0 , 0 5}$ & not & yes & yes & yes & yes \\
\hline & $\alpha=\mathbf{0 , 1}$ & not & yes & yes & yes & yes \\
\hline & $\alpha=0,2$ & not & yes & yes & yes & yes \\
\hline \multirow{4}{*}{ PE } & test & \multirow{4}{*}{$T 9$} & 5,85 & 6,89 & 2,59 & 7,18 \\
\hline & $\alpha=0,05$ & & yes & yes & yes & yes \\
\hline & $\alpha=0,1$ & & yes & yes & yes & yes \\
\hline & $\alpha=0,2$ & & yes & yes & yes & yes \\
\hline \multirow{4}{*}{ SZ } & test & \multirow{4}{*}{\multicolumn{2}{|c|}{$\begin{array}{l}1,96 \\
1,64 \\
1,28\end{array}$}} & 1,23 & 3,11 & 1,44 \\
\hline & $\alpha=0,05$ & & & not & yes & not \\
\hline & $\alpha=0,1$ & & & not & yes & not \\
\hline & $\alpha=0,2$ & & & not & yes & yes \\
\hline \multirow{4}{*}{ EU } & test & \multirow{4}{*}{\multicolumn{3}{|c|}{ yes - significant variation }} & 4,21 & 0,17 \\
\hline & $\alpha=0,05$ & & & & yes & not \\
\hline & $\alpha=0,1$ & & & & yes & not \\
\hline & $\alpha=0,2$ & & & & yes & not \\
\hline \multirow{4}{*}{ ST } & test & \multirow{4}{*}{\multicolumn{4}{|c|}{ not-insignificant variation }} & 4,46 \\
\hline & $\alpha=0,05$ & & & & & yes \\
\hline & $\alpha=0,1$ & & & & & yes \\
\hline & $\alpha=0,2$ & & & & & yes \\
\hline
\end{tabular}

Source: own study.

The analysis of Table 3 confirms that, comparing the average rating pointed by respondents for a couple of factors $\mathrm{CP}$ and $\mathrm{PE}$, is not significantly differentiated, whereas for the other factors entering into a relationship with a factor of continuous system problems detecting significance level of differentiation is important. Analyzing another factor - SZ factor - in the relationship with the EU, it can be seen that differences are not significant, but for a couple of factors SZ and ST the insignificant variation has been noted (for $\alpha=0.05$, $\alpha=0.1$ and for $\alpha=0.2$ ). In the case of a couple of factors $\mathrm{SZ}$ and $\mathrm{SW}$ it can be observed the variation is irrelevant for $\alpha=0.05$ and for $\alpha=0.1$. However, for $\alpha$ $=0.2$ differentiation is important. Average ratings of the EU and ST are relevant in each level $\alpha$. In the case of EU and SW factors relations there was no observed significance there is a difference. Examining ST and SW factors, it can be seen that the differentiation is important for all levels of $\alpha$.

\section{Summary and conclusions}

The study dealt with the E3 principle examination, which concerned the validity analysis of the production processes factors with regard to its significant differentiation. BOST study results distinguished primarily a factor concerning the production interruption after error detecting and the system of continuous problem detecting. In the opinion of the construction company workers the most important factor in the production process improvement are the following factors: interruption of production after an error is detected (PE) and subsequently qualitative factor (CP), i.e. continuous system of problem detecting.

\section{Additional information}

This work is connected to the scientific program of the „Improving quality of processes, products and services" BW 615/201/07. This project is supported by the Polish Ministry of Science and Higher Education.

\section{References}

1. BORKOWSKI S. 2012a. Documents containing invented term (TOYOTARYZM) and the name and structure of the elaborated method (BOST). Confirmation of the date. „AAK” KANCELARIA PATENTOWA s.c. Częstochowa.

2. BoRKOWsKI S. 2012b. Zasady zarzadzania Toyoty $w$ pytaniach. Wyniki badań BOST. Wy-dawnictwo PTM. Warszawa.

3. BoRKOWSKI S. 2012c. Toyotaryzm. Wyniki badań BOST. Wydawnictwo PTM. Warszawa.

4. Borkowski S. 2013d. Toyotarity. Term, Model, Range. Production Engineering Archives 1 (2013).

5. LIKER J.K. 2005. The Toyota Way. 14 Principles of management of the world's leading manu-facturing company. Publisher MT Business. Warsaw (Polish).

6. PUŁASKA-TURYNA B. 2008. Statistics for economists. Second edition. Diffin Editing company. Warsaw (Polish)

7. SELEJDAK J. 2013. Use of the Toyota management principles for evaluation of the company's mission. Production Engineering Archives 1 (2013). 